\title{
Prediction of mechanical behavior of friction stir welded joints of AA3003 aluminum alloy
}

\author{
I. Chekalil, A. Miloudi \\ University of Djillali Liabes, Laboratory of Materials and Reactive Systems (LMSR), Sidi Bel Abbès, Algeria \\ chekalil1ismail@gmail.com,miloudidz@yahoo.fr
}

\section{M.P. Planche}

University of technology Belfort-Montbeliard, Carnot de Bourgogne interdisciplinary laboratory (ICB-LERMPS), Belfort, France marie-pierre.planche@utbm.fr

\section{A. Ghazi \\ University of Mascara, Laboratory of Materials and Reactive Systems (LMSR), Mascara, Algeria ghaziaek@yahoo.fr}

\begin{abstract}
Friction stir welding (FSW) is an extremely complex process because it depends on the intrinsic and extrinsic factors of the material under consideration. The purpose of the present work is to formulate a set of recommendations concerning the choice of the different factors that are likely to influence the quality of the FSW joint and to find a mathematical model that allows predicting the mechanical behavior of the junction using response surface methodology (RSM). An experimental design was therefore used to highlight the effect of the welding parameters on the behavior of the aluminum alloy 3003 FS-Welded joint. Three inputs, namely feed rate, tool tilt angle and rotational speed are considered as input parameters and yield stress (YS ), ultimate tensile Strength (UTS) and rupture strength (RS) are treated as the outputs. The most influential parameters were shown to be in the order of rotational speed, feed rate and tool tilt angle. The study of the interactions between these different parameters made it possible to establish a number of combinations of the different factors, for the purpose of achieving the quality optimization of the FSW joint by obtaining a tensile strength of the weld joint equal to $75 \%$ of that of the base metal.
\end{abstract}

KEYwORDS. Friction stir welding; Mathematical model; Aluminum alloy 3003; Predicting.

\section{open ACCESS}

Citation: Chekalil, I., Miloudi, A., Planche, M.P., Ghazi, A., Prediction of mechanical behavior of friction stir welded joints of AA3003 aluminum alloy, Frattura ed Integrità Strutturale, 54 (2020) 153-168.

Received: 02.06 .2020

Accepted: 23.08 .2020

Published: 01.10.2020

Copyright: (c) 2020 This is an open access article under the terms of the CC-BY 4.0, which permits unrestricted use, distribution, and reproduction in any medium, provided the original author and source are credited. 


\section{INTRODUCTION}

$\mathrm{F}$ riction stir welding (FSW) is a complex process that is mainly attributed to thermal, mechanical, metallurgical phenomena, as well as to their combination during welding [1].This would make it very difficult to predict the quality of friction stir welding (FSW). It is interesting to note that the above phenomena depends on several parameters that can be classified into three categories, namely the process parameters, tool parameters and those related to the parts to be welded [2].

Numerous studies have investigated the mechanical properties of friction stir-welded joints of aluminum alloys. Some of these alloys are those:

- Suitable for heat treatment. These are alloys of types 2024 [3, 4], 7075 [5], 6061 [6, 7] and 6082 [8-10].

- With structural hardening. These are alloys of types 5456 [11] and 5059 [12].

These studies were carried out in order to assess the tensile and fatigue strengths of some aluminum joints.

As part of a study on the influence of the rotational speed, feed rate and tool tilt angle, on the mechanical properties of the AA 6061-T6 aluminum joint obtained through friction stir welding (FSW) [13], Wasif Safeen et al. succeeded in developing some mathematical models to determine these properties. The models developed allowed concluding that the rotational speed was more influential than the feed rate with regard to the tensile strength and ultimate impact resistance. However, the feed rate was shown to have higher effect than the rotational speed when it comes to achieving a good hardness level. They also showed that the optimization of the FSW process parameters makes it possible to obtain a tensile strength of $92 \%$, an impact toughness of $87 \%$ and impact hardness of $95 \%$ in comparison with the properties of the base metal.

As for Chetan and $\mathrm{Al}$ [14], they studied the evolution of the hardness profile for the different tool rotational speeds of 650 700, 800, 900, 1000 and transverse speed of 30,35, $40 \mathrm{~mm} / \mathrm{min}$ of AA7075T651 and AA6061T6 aluminum alloy. They found the parameters $(800 \mathrm{rpm}, 35 \mathrm{~mm} / \mathrm{min}$ ) and (900 rpm, $30 \mathrm{~mm} / \mathrm{min})$ give good quality of the weld.

On the other hand, Singh and Kaushik [15] found, during the friction stir welding (FSW) process of AA6061 and AA6082 aluminum alloys, maximum values for the tensile strength $(236 \mathrm{MPa})$ and for micro-hardness $(115 \mathrm{HV})$, under the operating conditions of $1400 \mathrm{rpm}$ for the tool rotational speed, $40 \mathrm{~mm} / \mathrm{min}$ for feed rate, and $2^{\circ}$ for tool tilt angle. However, the tensile strength would drop to a minimum value $165 \mathrm{MPa}$ under the operating conditions of $800 \mathrm{rpm}$ for the rotational speed, $60 \mathrm{~mm} / \mathrm{min}$ for feed speed, and $2^{\circ}$ for tool tilt angle.

As for K. Ramanjaneyulu et al. [16], they developed some mathematical models using a response surface methodology (RSM) to predict the yield stress (YS), the ultimate tensile strength (UTS) and the percent elongation (\% El) of friction stirwelded joints of the AA 2014-T6 alloy aluminum. Their results suggested that the most influential parameters are in the order of importance the rotational speed, feed rate, tool tilt angle and its profile. These same results indicated that the joints obtained by a hexagonal tool exhibited maximum tensile strength and elongation.

On the other hand, A. Heidarzadeh et al. [17] used the Design of Experiments technique to predict the tensile properties of FSW joints in AA 6061-T4 aluminum alloy. In their study, three welding parameters were considered, namely the tool rotational speed, feed rate and axial force. The results obtained showed that the optimal parameters of $920 \mathrm{rpm}$ for the tool rotational speed and $78 \mathrm{~mm} / \mathrm{min}$ for the feed rate enabled them to obtain high strength values, of the order of $7.2 \mathrm{kN}$ for the axial force.

K. Elangovan et al. [18] developed a mathematical model to predict tensile strength of the friction stir welded AA6061 aluminum alloy, four FSW parameters were studied: tool profile, rotational speed, welding speed and Axial force. Response surface method (RSM) has been used to develop the model. The authors concluded that the developed mathematical model can be effectively used to predict the tensile strength of FSW joints at $95 \%$ confidence level.

Recently, Srujan Manohar and K. Mahadevan [19] have predicted mechanical and microstructural behaviors of friction stir welded thin gauge aluminum-copper sheets. Weld-process parameters coded for tool-rotational speed, tool-travel speed and tool-plunge depth are examined for predicting better joint characteristics. The authors concluded that the maximum value of UTS and YS [191 MPa and $184 \mathrm{MPa}$ ] are observed for [1800 rot $/ \mathrm{min}$ and $80 \mathrm{~mm} / \mathrm{min}]$.

Due to the lack of investigations on the interaction between the tool tilt angle, rotational speed and feed rate of AA 3003 Aluminum alloy, the aim of this work is to study the effect of these parameters on the mechanical properties of friction stirwelded joints under tensile loading. The Design of Experiments technique was applied for the modeling and prediction of the behavior of the friction stir-welded joint of AA 3003 aluminum alloy. Response surface method (RSM) has been used to develop the model. In addition, determining the optimum parameters will lead to improved quality of FSW joints. 


\section{EXPERIMENTAL METHOD}

7 he friction stir welds were produced on a vertical milling machine using the friction stir welding tool presented in Fig. 1. In order to choose the FSW welding tool, preliminary tests were carried out on the tool itself; the geometry adopted is similar to that of a conical pin $(d=5 \mathrm{~mm}$ and $D=6.8 \mathrm{~mm}$, length $=1.7 \mathrm{~mm}$ with a $19.5 \mathrm{~mm}$ diameter flat shoulder), made out of X210Cr12 steel with a tensile strength TS $=870 \mathrm{MPa}$.

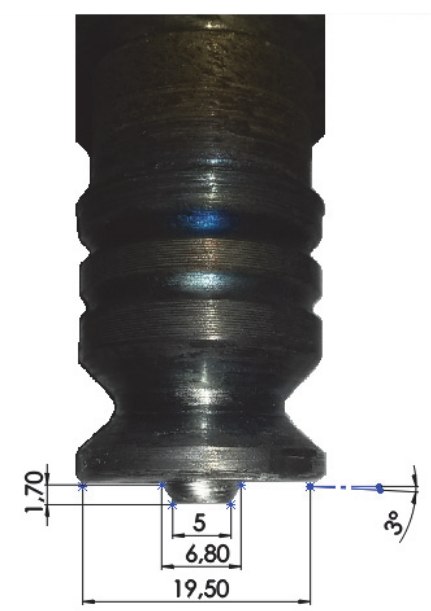

Figure 1: Tool geometry

Two AA 3003 aluminum plates, of dimensions $210 \mathrm{~mm} \times 110 \mathrm{~mm}$ and $2 \mathrm{~mm}$ thick, were joined along the rolling direction using the friction stir welding process. The initial joint configuration was obtained by securing the plates in position using mechanical clamps. Single-pass welding procedure was followed to fabricate the joints (Fig. 2-a). The cutting operation of samples on the welded plates is shown in the diagram presented in Fig. 2-b, where the geometric dimensions are expressed in $\mathrm{mm}$.
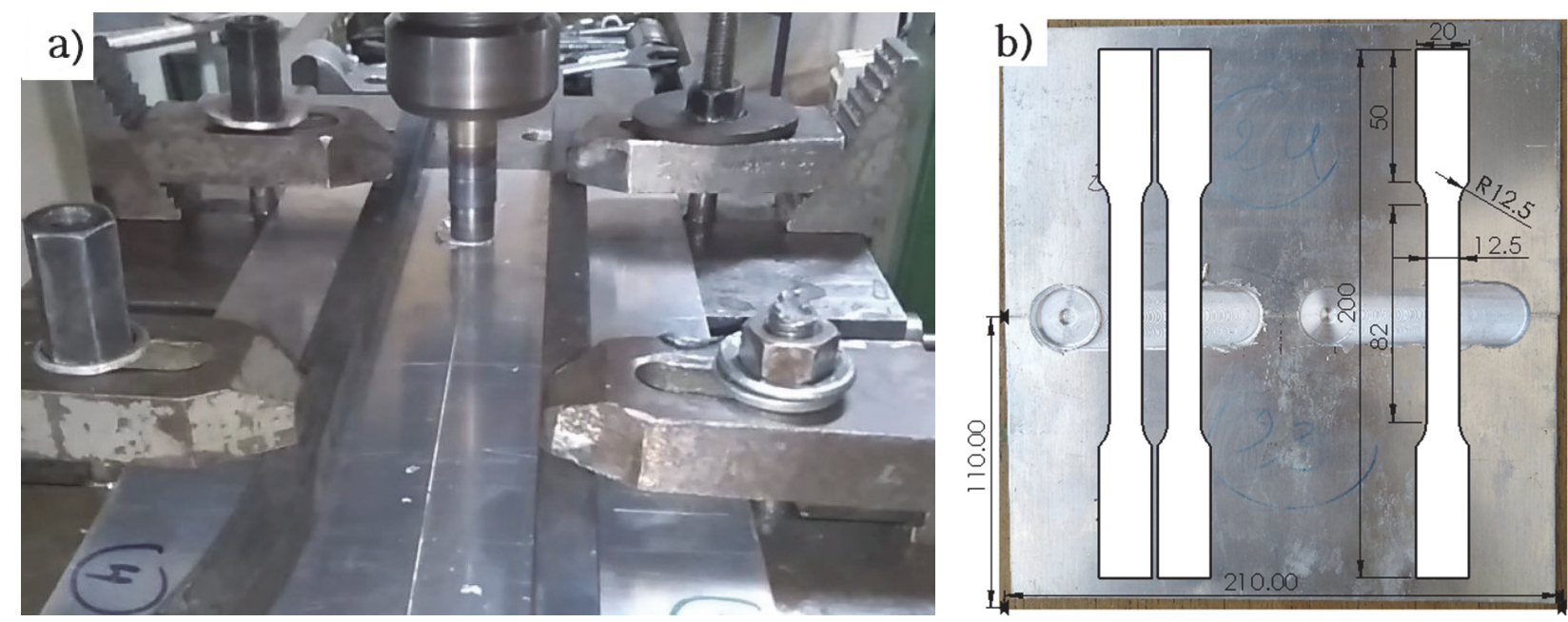

Figure 2: (a) FSW configuration; (b) Cutting of samples on welded plates according to ASTM E8M8 (dimensions in mm)

The tensile tests were carried out on an INSTRON tensile machine, controlled by the MTS software, as shown in Fig. 3. The chemical composition and mechanical properties of the base material before welding are reported in Tabs. 1 and 2. The chemical composition was obtained by SEM-EDX (Scanning Electron Microscopy - Energy Dispersive X-ray Analysis) method. 

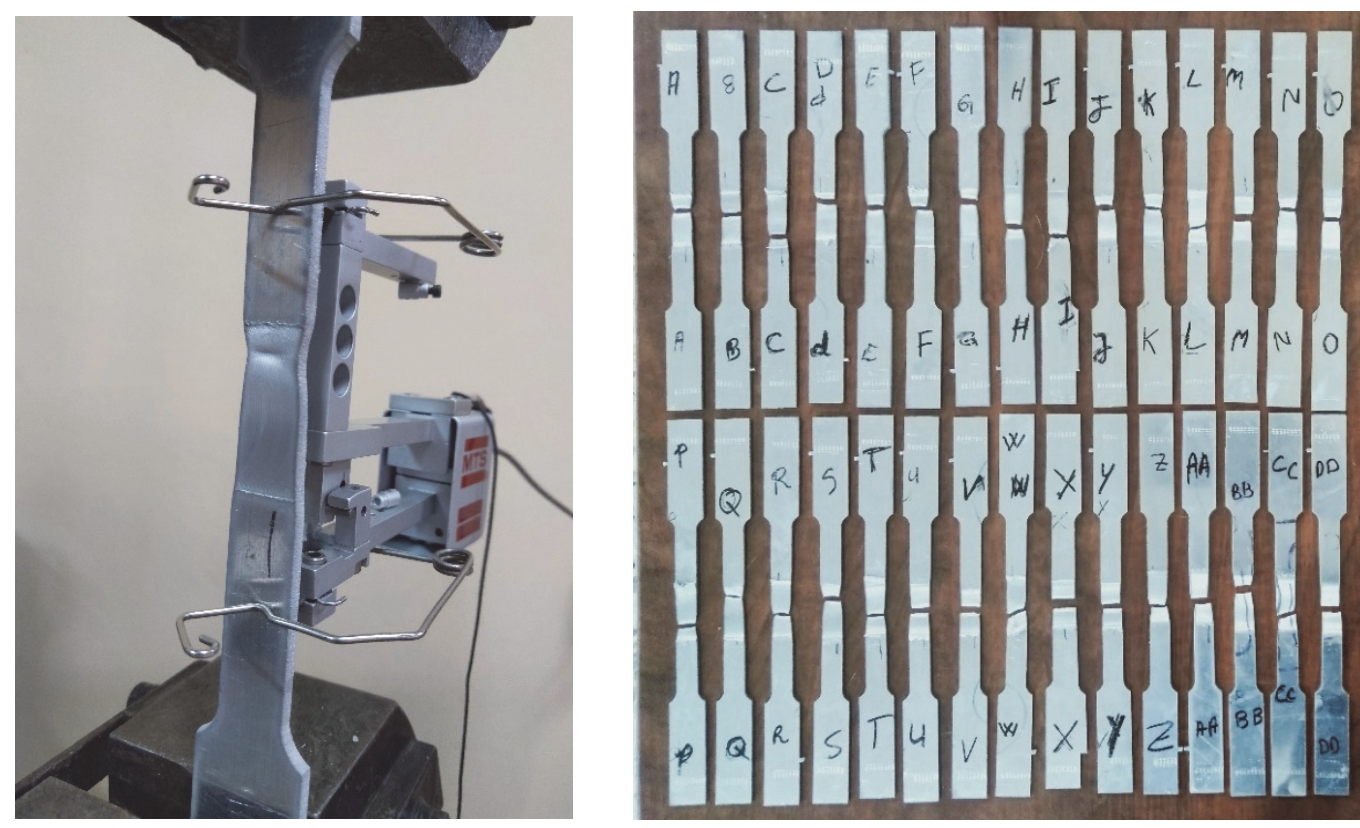

Figure 3: Dumbbell-shaped specimen tensile test measured by the extensometer

\begin{tabular}{lllllll}
\hline $\begin{array}{l}\text { Micro hardness } \\
(\mathrm{HV})\end{array}$ & YS (MPa) & UTS (MPa) & RS (MPa) & EL \% & YM (GPa) & $\begin{array}{l}\text { T Fusion } \\
\left({ }^{\circ} \mathrm{C}\right)\end{array}$ \\
51 & 110 & 160 & 127 & 5,6 & 60 & 650 \\
\hline
\end{tabular}

Table 1: Mechanical properties of the material before welding

\begin{tabular}{cccccccccccccccc}
\hline Element & $\mathrm{Al}$ & $\mathrm{Mn}$ & $\mathrm{Si}$ & $\mathrm{Fe}$ & $\mathrm{Cu}$ & $\mathrm{Ti}$ & $\mathrm{Zn}$ & $\mathrm{Mg}$ & $\mathrm{Cr}$ \\
$\%$ & 96,7 & 1,3 & 0,9 & 0,9 & 0,13 & 0,1 & 0,03 & 0 & 0 \\
\hline
\end{tabular}

Table 2: Chemical composition of the material before welding

Fig. 4 displays a typical example of the profile obtained during the tensile test; the important factors of the stress-stain curve of friction stir welding (FSW) joint profile (Output experimental results) are summarized in Tab. 3.

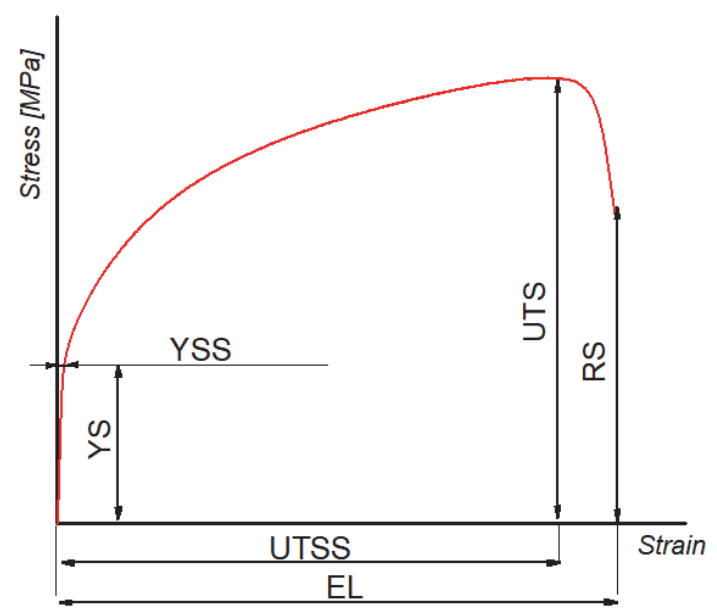

Figure 4: Typical stress-stain curve of friction stir welding (FSW) joint. 


\begin{tabular}{lll}
\hline & Factors & Outputs results \\
1 & YS & Yield Stress \\
2 & YSS & Yield Stress Strain \\
4 & UTS & Ultimate Tensile Strength \\
5 & UTSS & Ultimate Tensile Strength Strain \\
6 & RS & Rupture strength \\
\hline
\end{tabular}

Table 3: Output experimental results

The experimental design is used to identify a relationship between the input variables feed rate, tool tilt angle and rotational speed and the output variables (YS, YSS, UTS, UTSS, RS and EL). In order to predict the mechanical behavior of friction stir welded joints of AA3003 aluminum alloy. The response surface methodology (RSM) is used to develop the non-linear model of the FSW joints of aluminum alloys (AA 3003).

The optimization was carried out by a complete factorial plan with three factors, rotational speed $\mathrm{N}$, feed rate $\mathrm{S}$, and tool tilt angle $\mathrm{T}$, at three levels $(-1,0,+1)$. Tab. 4 below gives the values of each parameter for each level. The values of these parameters are dictated by the capacity of the machine and the tool wear premature.

\begin{tabular}{cccc}
\hline Parameters & low level -1 & Center level 0 & high level +1 \\
Rotation speed (rot/min) & 1000 & 1500 & 2000 \\
Feed rate $(\mathrm{mm} / \mathrm{min})$ & 200 & 300 & 400 \\
Tool tilt angle $\left(^{\circ}\right)$ & 0,5 & 1,5 & 2,5 \\
\hline
\end{tabular}

Table 4: Parameter values for each level

\section{DEVELOPING A MATHEMATICAL MODEL}

he software MODDE 5.0 (Modeling and Design) [20] is used for the model elaboration and the statistical analysis of the experimental design. If there is curvature in the system, then a polynomial of higher degree must be used, such as the second-order model. The model used has the quadratic form given below:

$$
y=a_{0}+\sum_{i=1}^{3} a_{i} x_{i}+\sum_{1 \leq j \leq 3} a_{i j} x_{j}+\sum_{i=1}^{3} a_{i i} x_{i}^{2}+e
$$

Where $a_{0}$ is the predicted response value at the center of the experimental domain, $a_{i}$ represents the effect of the factor $x_{i}$, and $a_{i j}$ stands for the interaction between the factor $x_{i}$ and $x_{j}$.

The Design of Experiments approach was applied to 30 tests, two replicates are considered for each combination of the input variables, which made it possible to define the coefficients summarized in Tab. 5. 


\begin{tabular}{|c|c|c|c|c|c|c|c|}
\hline Exp & $\begin{array}{c}\mathrm{N} \\
{[\mathrm{rot} / \mathrm{min}]}\end{array}$ & $\begin{array}{c}\mathrm{S} \\
{[\mathrm{mm} / \mathrm{min}]}\end{array}$ & $\begin{array}{c}\mathrm{T} \\
{\left[{ }^{\circ}\right]}\end{array}$ & $\begin{array}{c}\mathrm{YS} \\
{[\mathrm{MPa}]}\end{array}$ & $\begin{array}{c}\text { UTS } \\
{[\mathrm{MPa}]}\end{array}$ & $\begin{array}{c}\mathrm{RS} \\
{[\mathrm{MPa}]}\end{array}$ & $\begin{array}{l}\text { Fracture } \\
\text { location }\end{array}$ \\
\hline 1 & 1000 & 200 & 0,5 & 50,2 & 128,0 & 76,3 & TMAZ \\
\hline 2 & 1500 & 200 & 0,5 & 36,4 & 123,2 & 80,2 & Nugget \\
\hline 3 & 2000 & 200 & 0,5 & 26,6 & 123,8 & 78,7 & TMAZ \\
\hline 4 & 1000 & 300 & 0,5 & 40,4 & 103,7 & 63,0 & TMAZ \\
\hline 5 & 1500 & 300 & 0,5 & 33,8 & 102,8 & 78,4 & TMAZ \\
\hline 6 & 2000 & 300 & 0,5 & 24,3 & 97,8 & 74,6 & TMAZ \\
\hline 7 & 1000 & 400 & 0,5 & 58,7 & 125,9 & 75,2 & TMAZ \\
\hline 8 & 1500 & 400 & 0,5 & 33,8 & 109,8 & 87,6 & TMAZ \\
\hline 9 & 2000 & 400 & 0,5 & 21,4 & 98,4 & 72,0 & TMAZ \\
\hline 10 & 1000 & 200 & 1,5 & 36,2 & 100,3 & 75,1 & TMAZ \\
\hline 11 & 1500 & 200 & 1,5 & 41,9 & 118,4 & 90,7 & TMAZ \\
\hline 12 & 2000 & 200 & 1,5 & 43,1 & 121,1 & 85,0 & TMAZ \\
\hline 13 & 1000 & 300 & 1,5 & 34,7 & 94,7 & 77,7 & Nugget \\
\hline 14 & 1500 & 300 & 1,5 & 40,0 & 107,4 & 95,0 & TMAZ \\
\hline 15 & 2000 & 300 & 1,5 & 29,5 & 107,6 & 79,2 & Nugget \\
\hline 16 & 1000 & 400 & 1,5 & 39,4 & 109,1 & 88,7 & TMAZ \\
\hline 17 & 1500 & 400 & 1,5 & 43,3 & 115,6 & 89,1 & TMAZ \\
\hline 18 & 2000 & 400 & 1,5 & 38,1 & 127,8 & 86,9 & TMAZ \\
\hline 19 & 1000 & 200 & 2,5 & 20,5 & 92,5 & 65,3 & TMAZ \\
\hline 20 & 1500 & 200 & 2,5 & 22,9 & 100,1 & 79,7 & TMAZ \\
\hline 21 & 2000 & 200 & 2,5 & 43,9 & 120,1 & 78,0 & Nugget \\
\hline 22 & 1000 & 300 & 2,5 & 12,4 & 73,1 & 65,4 & Nugget \\
\hline 23 & 1500 & 300 & 2,5 & 32,5 & 106,8 & 85,4 & TMAZ \\
\hline 24 & 2000 & 300 & 2,5 & 29,2 & 110,6 & 72,7 & Nugget \\
\hline 25 & 1000 & 400 & 2,5 & 28,7 & 95,8 & 88,5 & Nugget \\
\hline 26 & 1500 & 400 & 2,5 & 31,7 & 113,6 & 95,2 & TMAZ \\
\hline 27 & 2000 & 400 & 2,5 & 39,7 & 120,0 & 73,0 & Nugget \\
\hline 28 & 1500 & 300 & 1,5 & 39,5 & 108,5 & 83,3 & TMAZ \\
\hline 29 & 1500 & 300 & 1,5 & 40,2 & 108,2 & 90,0 & TMAZ \\
\hline 30 & 1500 & 300 & 1,5 & 43,5 & 107,9 & 86,1 & Nugget \\
\hline
\end{tabular}


The developed mathematical models make it possible to establish a relationship between the input parameters $(\mathrm{N}, \mathrm{S}$ and $\mathrm{T})$ and the output quantities (YSS, YS, UTSS, UTS, EL and RS). The polynomials help optimize the welding parameters in order to reach the desired responses. To calculate the coefficients of the models, a regression method based on the least squares criterion is used. The mathematical models suggested by MODDE 5.0 are:

$$
\begin{aligned}
\mathrm{YS}= & 80,403+0,006 \cdot N-0,199 \cdot S-17,805 \cdot T-5,72 \cdot 10^{-5} \cdot N \cdot S+0,0214 \cdot N \cdot T+0,0101 \cdot S \cdot T-7,84 \cdot 10^{-6} \cdot N^{2}+ \\
& +4,62 \cdot 10^{-4} \cdot S^{2}-6,944 \cdot T^{2} \\
\mathrm{UTS}= & 217,617+0,033 \cdot N-0,744 \cdot S-38,764 \cdot T-4,8 \cdot 10^{-5} \cdot N \cdot S+0,021 \cdot N \cdot T+0,048 \cdot S \cdot T-1,29 \cdot 10^{-5} \cdot N^{2}+ \\
& +0,0012 \cdot S^{2}-3,95 \cdot T^{2} \\
\text { RS }= & -9,834+0,146 \cdot N-0,208 \cdot S+16,76 \cdot T-7,58 \cdot 10^{-5} \cdot N \cdot S-0,001 \cdot N \cdot T+0,028 \cdot S \cdot T-3,96 \cdot 10^{-5} \cdot N^{2}+ \\
& +5,08 \cdot 10^{-4} \cdot S^{2}-7,585 \cdot T^{2} \\
\text { YSS }= & 0,0032-1,55 \cdot 10^{-6} \cdot \mathrm{N}-3,81 \cdot 10^{-6} \cdot S-7,013 \cdot 10^{-4} \cdot \mathrm{T}-7,76 \cdot 10^{-10} \cdot \mathrm{N} \cdot \mathrm{S}+4,436 \cdot 10^{-7} \cdot \mathrm{N} \cdot \mathrm{T}+8,42 \cdot 10^{-7} \cdot \mathrm{S} \cdot \mathrm{T}+ \\
& +3,02 \cdot 10^{-10} \cdot \mathrm{N}^{2}+6,33 \cdot 10^{-9} \cdot S^{2}-8,73 \cdot 10^{-5} \cdot \mathrm{T}^{2} \\
\mathrm{UTSS} & =0,09+8,03 \cdot 10^{-5} \cdot \mathrm{N}-3,55 \cdot 10^{-4} \cdot \mathrm{S}-5,71 \cdot 10^{-4} \cdot \mathrm{T}+1,29 \cdot 10^{-7} \cdot \mathrm{N} \cdot \mathrm{S}+ \\
& +1,269 \cdot 10^{-5} \cdot \mathrm{N} \cdot \mathrm{T}-6,626 \cdot 10^{-5} \cdot \mathrm{S} \cdot \mathrm{T}-4,03 \cdot 10^{-8} \cdot \mathrm{N}^{2}+3,69 \cdot 10^{-7} \cdot \mathrm{S}^{2}-0,0022 \cdot \mathrm{T}^{2} \\
\mathrm{EL}= & 0,1197+6,181 \cdot 10^{-5} \cdot \mathrm{N}-4,113 \cdot 10^{-4} \cdot S-0,0058 \cdot T+8,485 \cdot 10^{-8} \cdot N \cdot S+ \\
& +1,463 \cdot 10^{-5} \cdot N \cdot T-4,66 \cdot 10^{-5} \cdot S \cdot T-3,193 \cdot 10^{-8}-8 \cdot N^{2}+5,342 \cdot 10^{-7} \cdot S^{2}-0,0026 \cdot T^{2}
\end{aligned}
$$

\section{ANALYSIS OF RESULTS}

$\mathrm{F}$

ig. 5 gives the true stress - true strain curve which illustrates the elastoplastic behavior of aluminum 3003, the experiments are repeated two times, and the mean value is indicated on the graph.

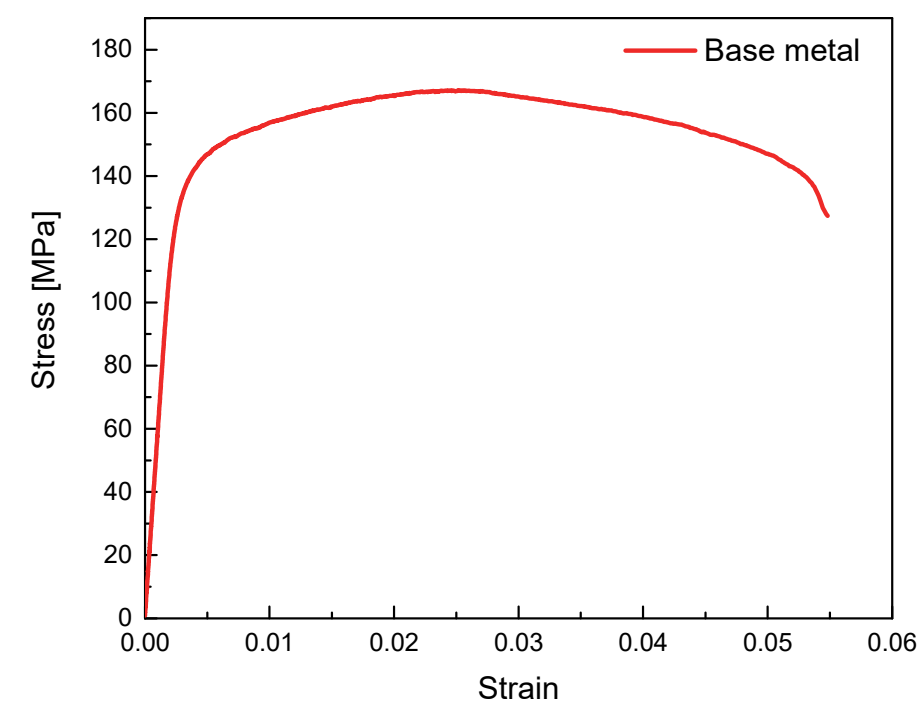

Figure 5: true stress - true stain curve of 3003 aluminum alloy. 
Fig. 6 presents three combination among the tensile tests carried out, that shows the effect of tool rotational speed on the mechanical behavior of the joint. This figure shows that the tensile strength is maximum when the rotational speed is equal to $1500 \mathrm{tr} / \mathrm{min}$, they reach a low value for a rotational speed equal to $1000 \mathrm{tr} / \mathrm{min}$. This speed must be adjusted in to optimize it.

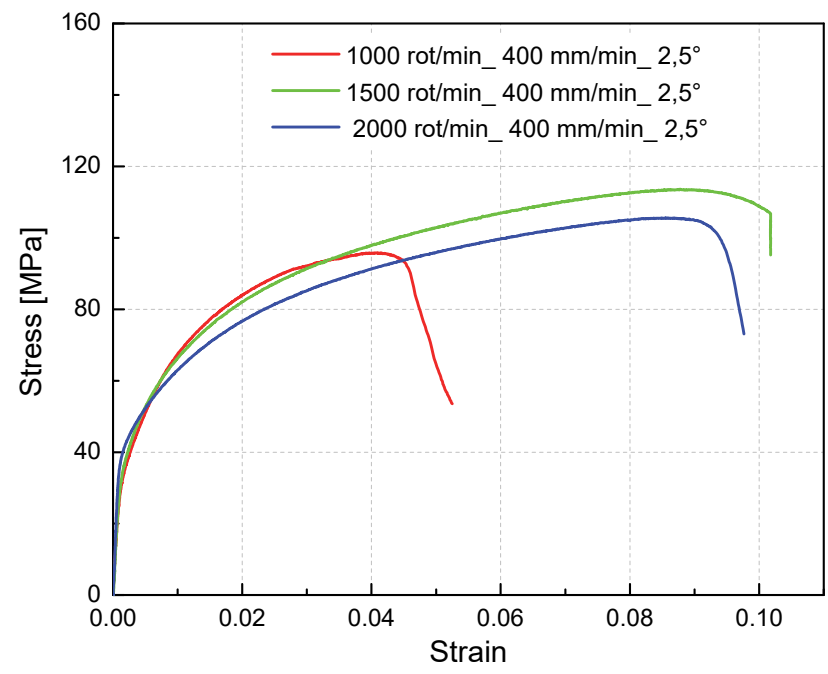

Figure 6: Effect of tool rotational speed on the mechanical behavior of the joint.

The values of the coefficients associated with the welding parameters in the mathematical model show the degree of influence of each factor. An example of prediction is given in Fig. 7. It is worth mentioning that Model (2) may be used to predict the evolution of the elastic limit as a function of the input parameters $\mathrm{N}, \mathrm{S}$ and $\mathrm{T}$. The central curves represent the predicted values, and the two other curves show the $95 \%$ confidence interval of the predicted response.
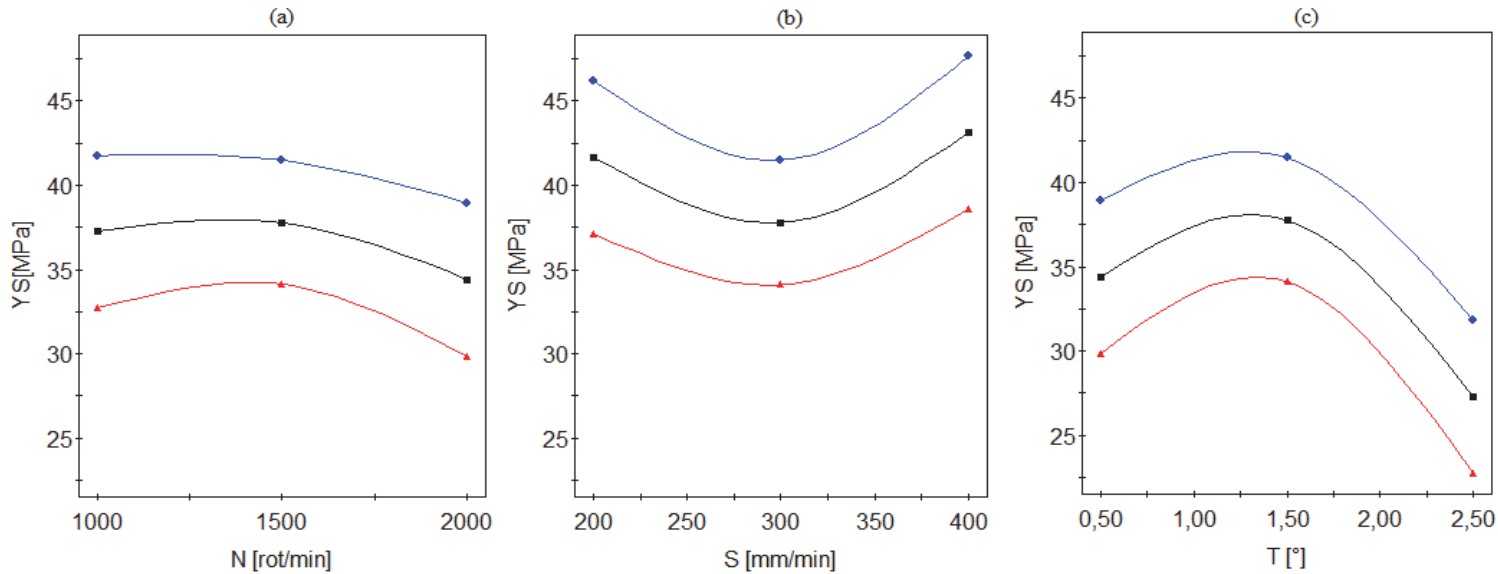

Figure 7: Evolution of the elastic limit $(\mathrm{MPa})$ as a function of the input data $(N, S$ and $T)$

Analysis of Fig. 7-a suggests that an increase in the rotational speed $N$ involves a slight reduction in the elastic limit. In fact, a $100 \%$ increase in the rotational speed leads to a reduction of around $9 \%$ in the elastic limit. This elastic limit is maximal when the speed value is equal to $1500 \mathrm{rot} / \mathrm{min}$.

Consequently, it can be concluded that increasing the rotational speed induces a slight decrease in the elastic limit YS.

Furthermore, Fig. 7-b indicates that the increase in the feed rate leads first to a decrease in the elastic limit, then to its increase beyond $300 \mathrm{~mm} / \mathrm{min}$. Based on the analysis of these curves, it can be assumed that there is a critical feed rate ( $S_{c r}=300 \mathrm{~mm} / \mathrm{min}$ ) above which the trends reverse. In this context, Mishra et al. [21] studied the effect of the feed rate on the mechanical characteristics of the friction stir-welded joints. They found out that an excessive increase in the feed rate induces internal macropore-type defects and tunnel-shaped defects. These defects can lead to a reduction in the mechanical properties of the welded joints. 
Fig. 7-c depicts the variation of the elastic limit as a function of the tool tilt angle. It can be seen that when the tilt angle increases, the elastic limit increases slightly and then starts decreasing thereafter; the maximum value of the elastic limit is obtained for an angle of $1.5^{\circ}$.

For the purpose of determining the effect of the rotational speed on the ultimate tensile strength Fig. 8-a, it was decided to vary the rotational speed $\mathrm{N}$. It is noted that the ultimate tensile strength increases with increasing rotational speed, which is in good agreement with the results obtained by A. Takhakh et al.[22] The ultimate tensile strength is maximum for a rotational speed of $2000 \mathrm{rot} / \mathrm{min}$; it then begins to decrease until reaching a minimum value for the rotational speed of $1000 \mathrm{rot} / \mathrm{min}$. Regarding the impact of feed rate Fig. 8-b, it can be noted that when the feed rate S increases, the ultimate tensile strength (UTS) decreases at first, then starts increasing to reach a maximum value for the two speed values of $200 \mathrm{~mm} / \mathrm{min}$ and $400 \mathrm{~mm} / \mathrm{min}$. In addition, it can be observed that the UTS is maximum for extreme values of S, which is contrary to the results previously published by B. Abnar et al. [23], which illustrated through a study the effects of heat input on microstructure and mechanical properties of the welded samples were investigated by changing the ratios of rotational speed (800-1200 r/min) to travel speed $(40-100 \mathrm{~mm} / \mathrm{min})$, who have indicated that the UTS values of the friction stir-welded joints of $3003-H 18$ aluminum are insensitive to the welding parameters $\mathrm{N}$ and $\mathrm{S}$.

Fig. 8-c illustrates the effect of the tilt angle on the ultimate tensile strength (UTS). It is clearly noted that the UTS is constant within the interval between $0.5^{\circ}$ and $1.5^{\circ}$, which is in agreement with the results reported by Y. Birol et al. [24] In addition, it can be noted that the effect of feed rate $(\mathrm{S})$ and tilt angle $(\mathrm{T})$ on the ultimate tensile strength is similar to that observed on the elastic limit (YS).
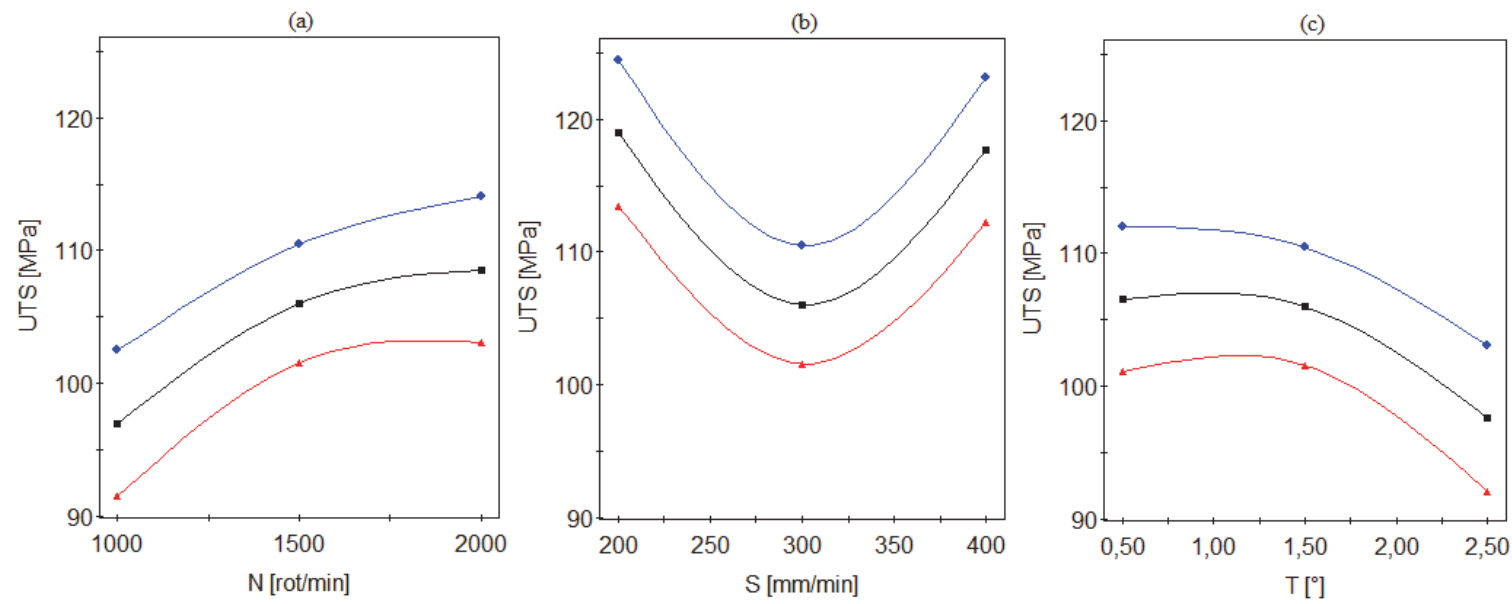

Figure 8: Evolution of the ultimate tensile strength $(\mathrm{MPa})$ as a function of the process parameters.

This last part focuses on the study of the effect of the welding parameters on the evolution of the rupture strength. Fig. 9a shows that an increase in the rotational speed causes the rupture strength to go up from $77 \mathrm{MPa}$ to a maximum value of $88 \mathrm{MPa}$, and then starts declining. It can therefore be said that there is a critical value of the rotational speed ( Nor $=1500 \mathrm{rot} / \mathrm{min}$ ) above which the rupture strength decreases.

The response of the rupture strength predicted by software MODDE 5.0 is represented on the Fig. 9-b in order to illustrate the impact of the feed rate. Indeed, an increase in the feed rate S, within the interval between 200 and $300 \mathrm{~mm} / \mathrm{min}$, engenders a slight decrease in the rupture strength. Beyond the value of $300 \mathrm{~mm} / \mathrm{min}$, the tensile strength starts going up to reach a maximum value of $96 \mathrm{MPa}$.

Similarly Fig. 9-c shows the effect of the tilt angle on the rupture strength. It is clearly seen that, at first, the increase in T leads to an increase in the rupture strength from the value $80 \mathrm{MPa}$ for the angle $0.5^{\circ}$ to a maximum value of $87 \mathrm{MPa}$ for $1.5^{\circ}$; it then goes down to $81 \mathrm{MPa}$ for a maximum angle of $2.5^{\circ}$. Moreover, the results obtained show that there is a critical tilt angle $\mathrm{T} r \mathrm{r}=1.5^{\circ}$ beyond which the tensile strength starts decreasing.

In this analysis step, it was decided to broaden the scope of our study by taking into account the interaction between two factors. This allows viewing the output parameters on a three dimensional (3D) graph (Fig. 10); this graph depicts the variation of $\mathrm{YS}$ as a function of the two factors $\mathrm{N}$ and $\mathrm{S}$. 

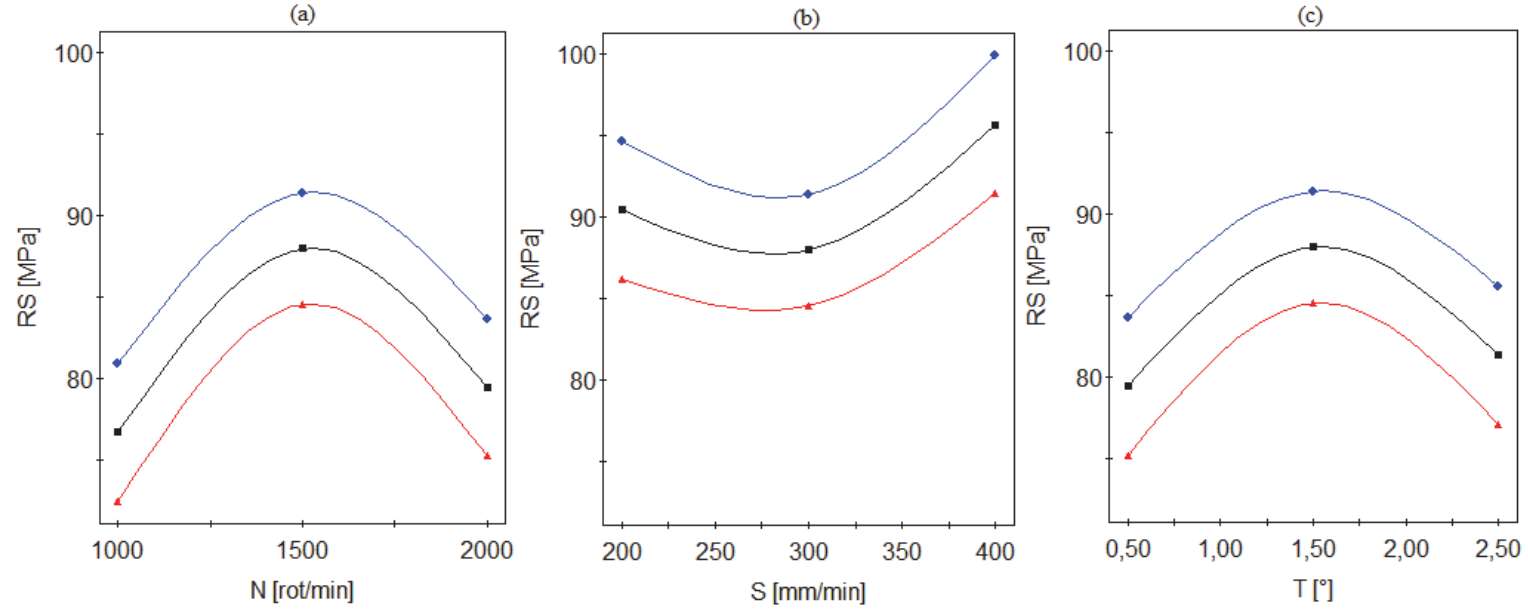

Figure 9: Evolution of the rupture strength $(\mathrm{MPa})$.

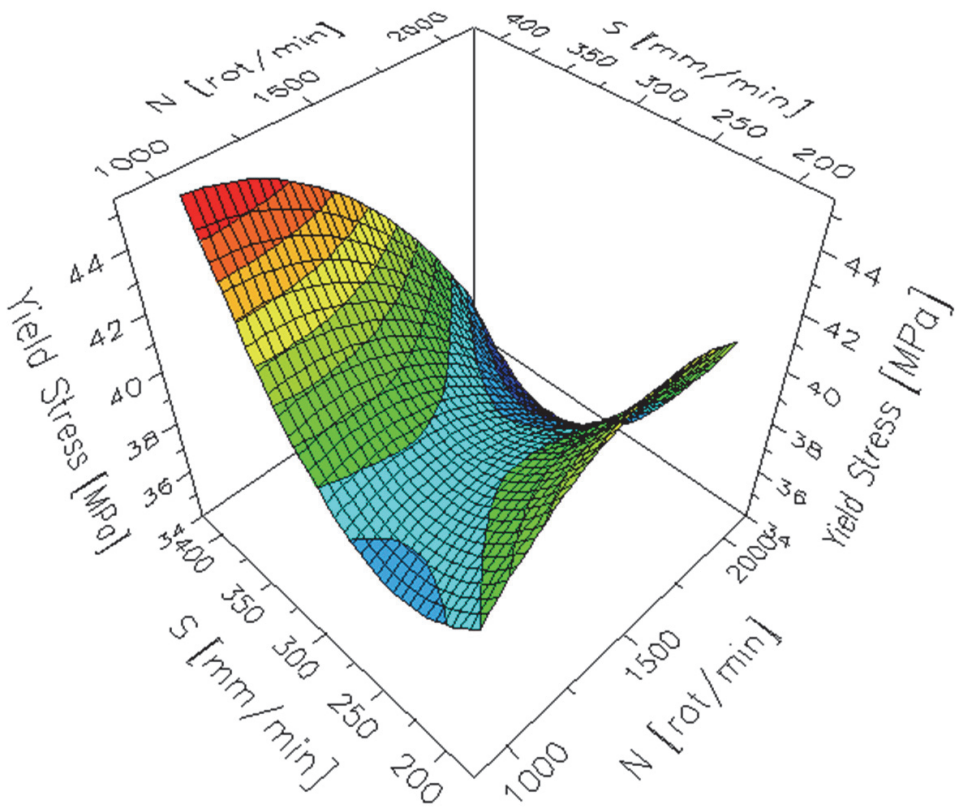

Figure 10: Three-dimensional (3D) variation of $\mathrm{YS}$ as a function of $\mathrm{N}$ and $\mathrm{S}$

The curves in Fig. 11, usually called 'Iso curves', correspond to the projection of the surface on the plane. Fig. 11-a shows that the more the rotational speed is reduced, the more the elastic limit rises until reaching a maximum value of $45 \mathrm{MPa}$. Note that this is only valid for a value of $\mathrm{N}$ between 1000 and $1200 \mathrm{rot} / \mathrm{min}$, because beyond this value, $\mathrm{N}$ has a negative effect on the elastic limit (YS). On the other hand, the low figures of YS were recorded for the maximum values of $N=2000 \mathrm{rot} / \mathrm{min}$, and $\mathrm{S}$ between 280 and $370 \mathrm{~mm} / \mathrm{min}$. It is also worth noting that the best elastic limit values of the weld joint were obtained for a ratio $(N / S)$ between 2.5 and 3 .

Consequently, it may be concluded that to have a high elastic limit (YS), it is necessary to take $S=400 \mathrm{~mm} / \mathrm{min}$ and $\mathrm{N}$ between 1000 and $1200 \mathrm{rot} / \mathrm{min}$.

In Fig. 11-b, the quantity $S$ is fixed on $300 \mathrm{~mm} / \mathrm{min}$, while $\mathrm{T}$ and $\mathrm{N}$ are varied. In this type of interactions, the elastic limit (YS) is large while the two factors $\mathrm{T}$ and $\mathrm{N}$ take minimum values. Consequently, in order to increase the elastic limit (YS), it is necessary to decrease $\mathrm{N}$ and $\mathrm{T}$.

Finally, Fig. 11-c illustrates the variation of YS as a function of factors T and S. In this case, YS exhibits high values for two intervals; the first interval corresponds to a feed rate (S) equal to $200 \mathrm{~mm} / \mathrm{min}$ and tilt angle $\mathrm{T}$ between $0.8^{\circ}$ and $1.52^{\circ}$, 
and the second interval corresponds to $S=400 \mathrm{~mm} / \mathrm{min}$ and T between $1.1^{\circ}$ and $1.48^{\circ}$. However, the low values of elastic limit (YS) are recorded for values of S between 220 and $340 \mathrm{~mm} / \mathrm{min}$, and $\mathrm{T}$ between $2.4^{\circ}$ and $2.6^{\circ}$.

All these findings turned out to be in good agreement with those obtained by Wim Van et al. [25] who indicated that the appearance of defects depends on the choice of the tilt angle. They found out that the best mechanical properties are obtained for the optimal tilt angle value of $2^{\circ}$, which makes it possible to obtain the best mechanical properties. In addition, it was found that the best values of the elastic limit (YS) of the welded joint are equal to $53 \%$ of those of the base metal.

(a)

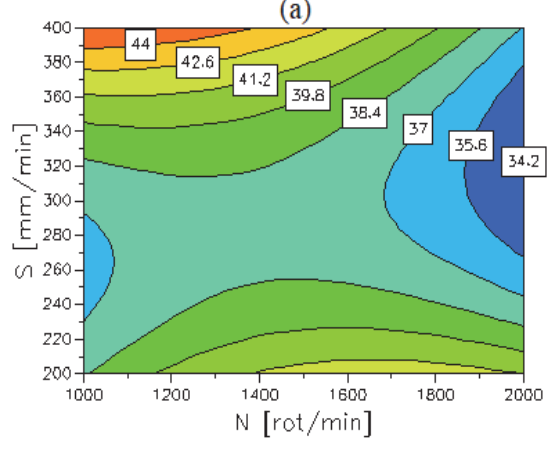

(b)

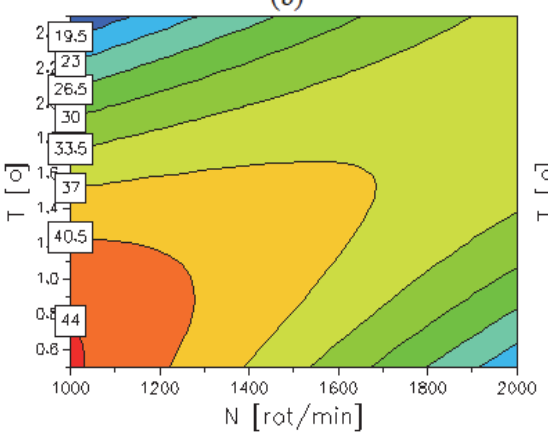

(c)

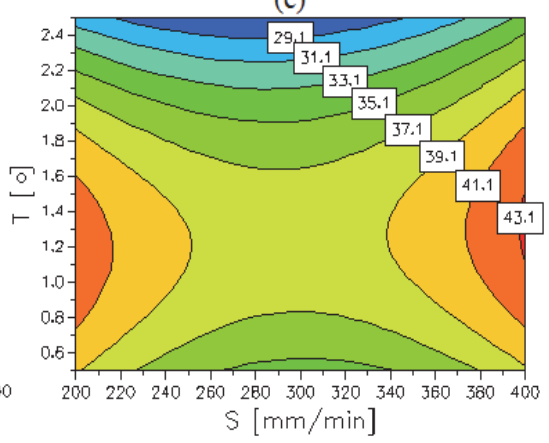

Figure 11: Variation of YS as a function of the three factors

Fig. 12-a presents the effect of the two factors $\mathrm{N}$ and $\mathrm{S}$ acting simultaneously on the ultimate tensile strength (UTS), passing from their minimum values to their maximum values while the third factor $(\mathrm{T})$ is kept constant.

Analysis of the graph in this figure suggests that the more $\mathrm{N}$ increases, the more the tensile strength also increases until reaching the maximum value of $121.2 \mathrm{MPa}$, while $\mathrm{S}$ is between 200 and $210 \mathrm{~mm} / \mathrm{min}$. In addition, it should also be noted that the UTS can reach values closer to the maximum values for maximum $\mathrm{S}$ equal to $400 \mathrm{~mm} / \mathrm{min}$ and for $\mathrm{N}$ between 1300 and $2000 \mathrm{rot} / \mathrm{min}$. On the other hand, low UTS values are recorded for low values of $\mathrm{N}$ around $1000 \mathrm{rot} / \mathrm{min}$. It is also worth mentioning that the best ultimate tensile strength (UTS) figures of the weld joint are found equal to $81 \%$ of those of the base metal.

Consequently, it can be concluded from this analysis that a maximum value of UTS is obtained for a value of N between 1700 and $2000 \mathrm{rot} / \mathrm{min}$, while keeping the value of S constant and equal to $200 \mathrm{~mm} / \mathrm{min}$.

This new section aims to present the response surface obtained when the value of $\mathrm{S}$ is kept constant, while varying $\mathrm{N}$ and T. It can be seen that the Ultimate Tensile Strength (UTS) takes maximum values within two interaction intervals; the first interval corresponds to $\mathrm{T}$ less than $0.7^{\circ}$ and $\mathrm{N}$ between 1000 and $1350 \mathrm{rot} / \mathrm{min}$, and the second one is for $\mathrm{T}$ between $1.2^{\circ}$ and $3^{\circ}$, while $\mathrm{N}$ is in the interval from 1700 to $2000 \mathrm{rot} / \mathrm{min}$. It is noted that the best Ultimate Tensile Strength (UTS) values of the weld joint are equal to $80 \%$ of those of the base metal.

On the other hand, Fig. 12-c illustrates the variation of the ultimate tensile strength (UTS) as a function of S and T. It is found that the simultaneous decrease in S and T leads to an increase in UTS; however, the simultaneous increase of $\mathrm{S}$ and $\mathrm{T}$ leads to a decrease in the magnitude of UTS. This effect is more pronounced when T is between 2.3 and $2.6^{\circ}$ and S within the interval from 240 to $330 \mathrm{~mm} / \mathrm{min}$.

(a)

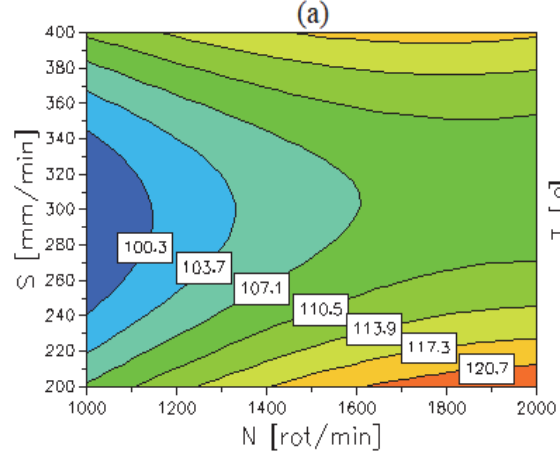

(b)

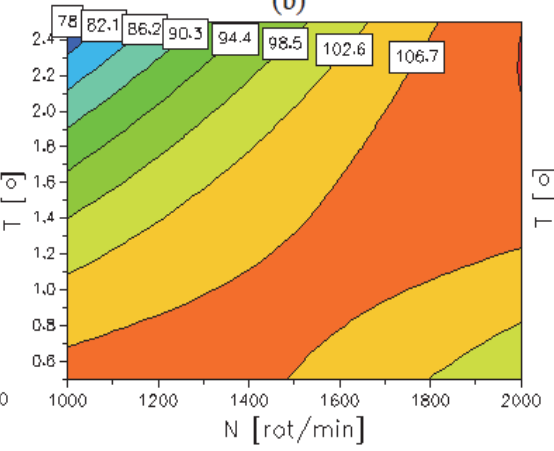

(c)

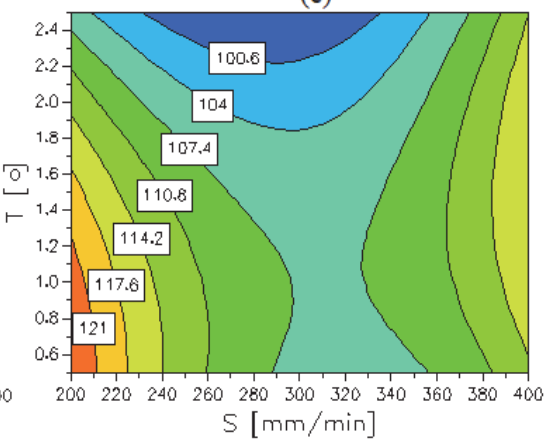

Figure 12: Evolution of UTS as a function of the three factors N, S and T 
Furthermore, Fig. 13 presents the predicted response (RS) as a function of the three factors $(\mathrm{N}, \mathrm{S}$ and $\mathrm{T})$. Analysis of the curve in this figure shows that a maximum value for the rupture strength is obtained when the value of $\mathrm{T}$ is between 1.3 and $1.55^{\circ}$, and that of $\mathrm{N}$ is within the interval from 1300 to $1650 \mathrm{rot} / \mathrm{min}$, and $\mathrm{S}$ is maintained at $400 \mathrm{~mm} / \mathrm{min}$.

Considering all these data, it therefore seems important to study the effect of these different factors on the mechanical properties of the welded joint. First, it is recommended to identify the factors that have the greatest influence and then determine the quantities that react with these factors.
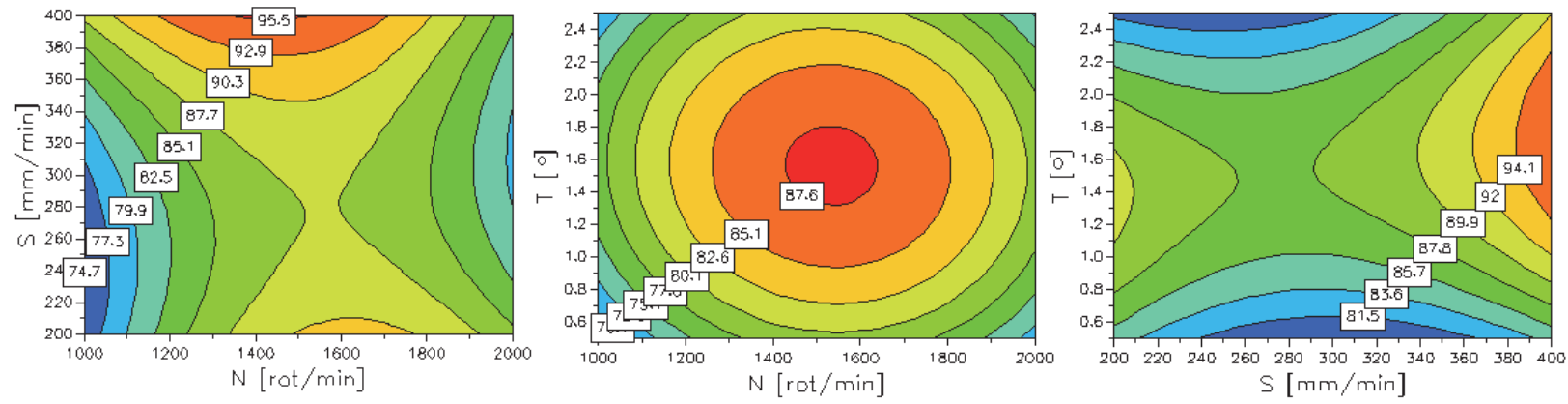

Figure 13: Evolution of UTS as a function of the three factors N, S and T

Figs. 14, 15 and 16 show the most influential parameters on YS, UTS and RS, respectively.

Fig. 14 shows that the factors that have the most influence on YS are in the following order: the tilt angle, then the rotational speed and finally the feed rate. Note also that the interaction effect between $\mathrm{N}$ and $\mathrm{S}$ is the most important, but the interaction effect between $\mathrm{S}$ and $\mathrm{T}$ is small. We find that the following coefficients $\mathrm{N}, \mathrm{S}$ and $\mathrm{S} * \mathrm{~T}$ are low compared to the others and will therefore be neglected later in Eqn. 2 of the proposed model. This suggests that there are very few linear effects for the parameters $\mathrm{N}$ and $\mathrm{S}$. Also, we find that increasing the rotational speed and tool tilt angle decreases yield strength.

Analysis of Fig. 15 indicates that the factors that have most effect on UTS are in the following order: rotational speed, tilt angle and feed rate. Also, it is found that the interactions between the factors are statistically significant, except that between rotational speed and tilt angle.

The last interaction study between the dominant factors focuses on the predicted response RS. Analysis of Fig. 16 indicates that the factors that have most effect on response RS are in the following order of importance: feed rate, rotational speed and tilt angle. In addition, it turns out that the interaction between rotational speed and feed rate, and feed rate and tilt angle have a greater influence on RS, except for the one between $\mathrm{N}$ and $\mathrm{T}$. Therefore, we find that increasing the rotational speed, tool tilt angle and the feed rate increases rupture strength. It can also be seen that the following coefficients $\mathrm{N}, \mathrm{S}$ and $\mathrm{N} * \mathrm{~T}$ are weak compared to the others and will therefore be neglected subsequently in Eqn. 4 of the proposed model.

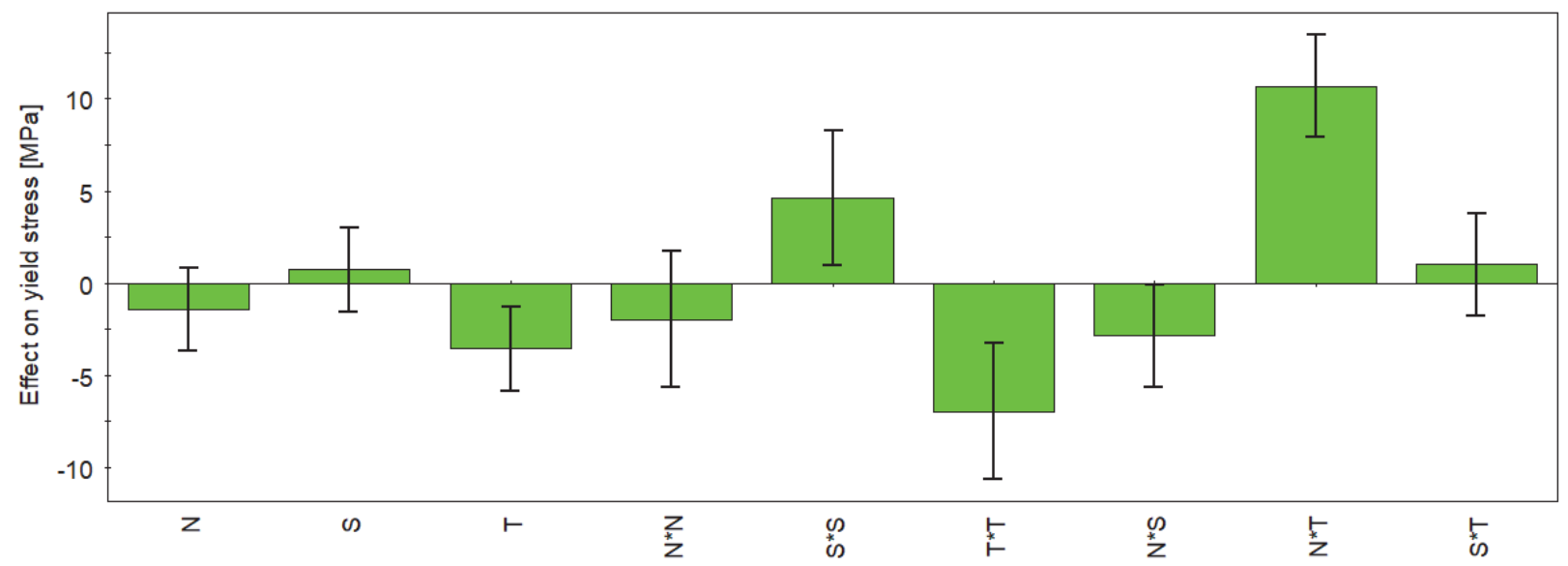

Figure 14: Effects of factors on YS and their interaction 


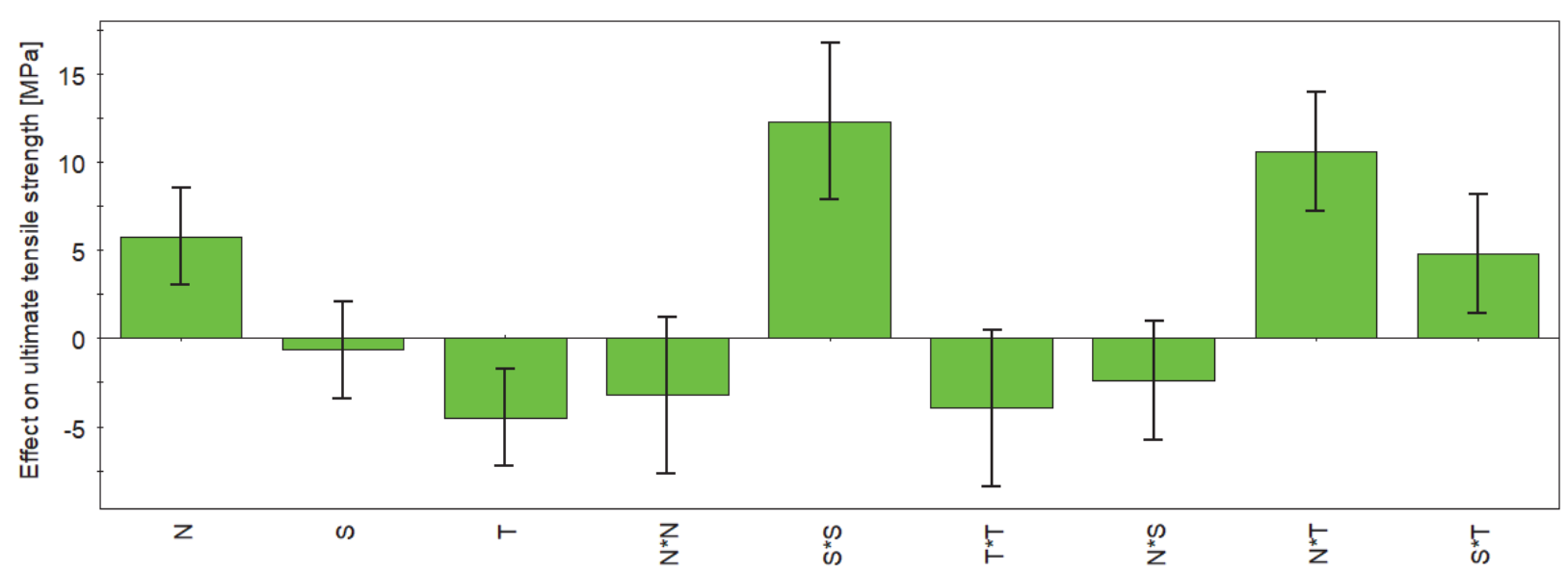

Figure 15: Effects of factors on UTS and their interaction.

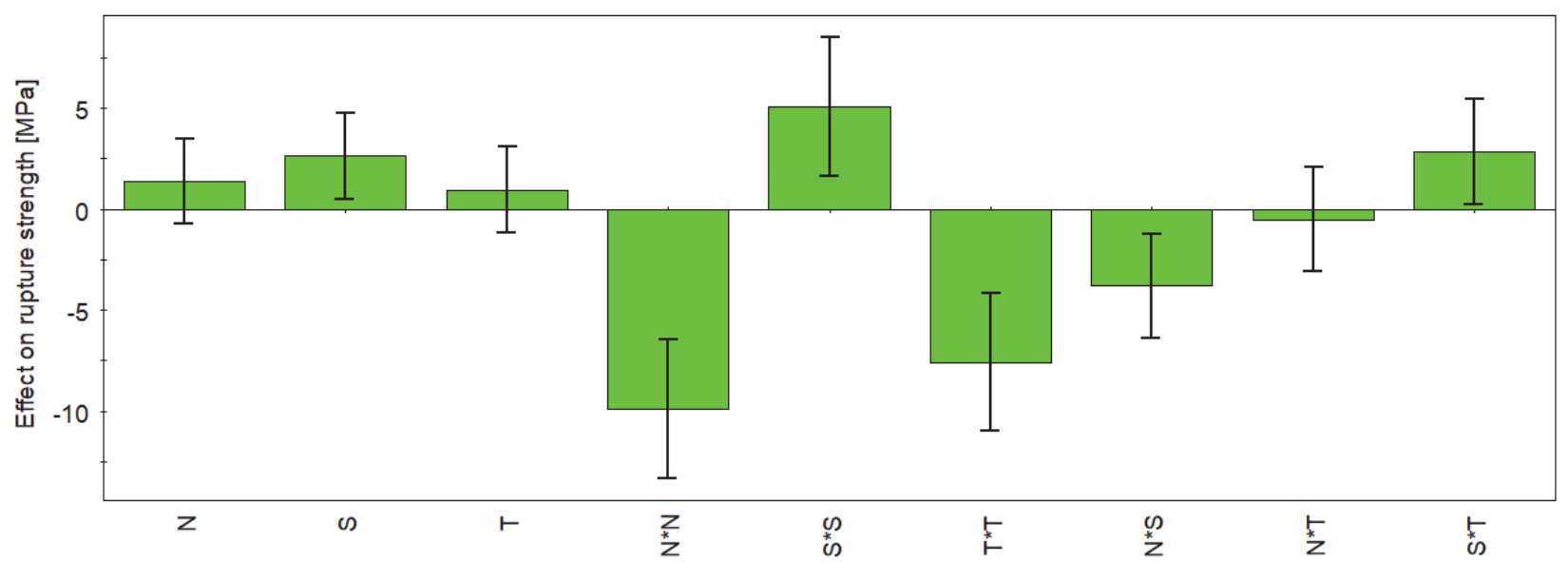

Figure 16: Effects of factors on RS and their interaction.

The validation of the models is done by comparing the experimental results with those obtained by the proposed models. Twenty-seven test cases are generated at random by assigning intermediate values to the process variables and for each combination, by changing the rotational speed (1000-2000 rot/min), travel speed (200-400 mm/min) and tool tilt angle $(0.5-$ $2.5^{\circ}$ ). Fig. 17 shows this comparison, we see that the relative differences obtained are between $0.23 \%$ and $6.07 \%$ for YS, from $0.13 \%$ to $6.35 \%$ for UTS and from $0.29 \%$ to $4.74 \%$ for RS. Figs. 17 -a, $17-b$ and 17 -c show a good correlation between the experimental results and the proposed models. However, the results obtained by the predicted models are closer to reality.

Tab. 6 below presents the optimized parameter values that allow obtaining the best mechanical properties of a welded joint. These values are achieved through the maximization of YS, UTS and RS; they correspond to the values of $N=1423.93 \mathrm{rot} / \mathrm{min}, S=400 \mathrm{~mm} / \min$ and $T=1.2885^{\circ}$.

The validation of these models is achieved by comparing the suggested optimized welding with those acquired by the predicted models Fig. 18, for a rotation speed equal to $1425 \mathrm{rot} / \mathrm{min}$, a feed rate equal to $400 \mathrm{~mm} / \mathrm{min}$ and a tilt angle of $1.3^{\circ}$.

Note that the results calculated with the proposed model are in agreement with the experimental ones. This model therefore makes it possible to obtain a better prediction of the mechanical behavior of a welded joint. 
(a)

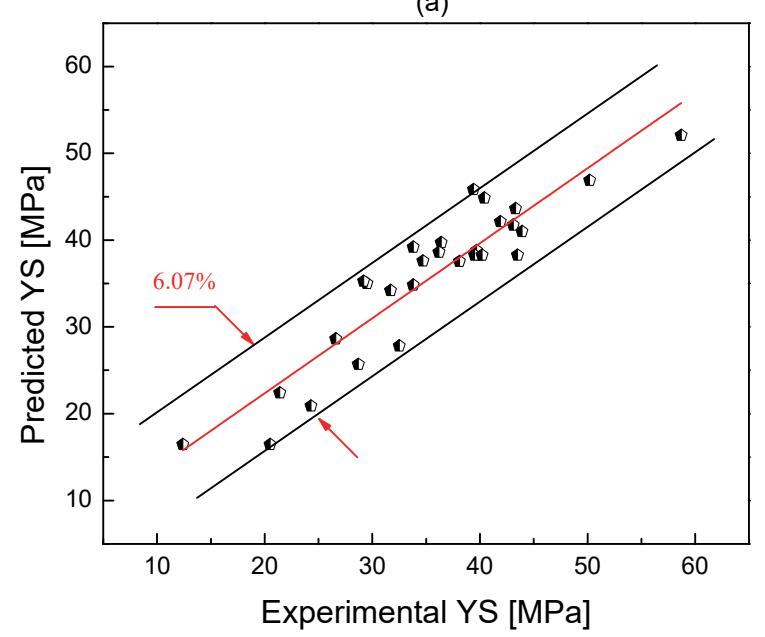

(b)

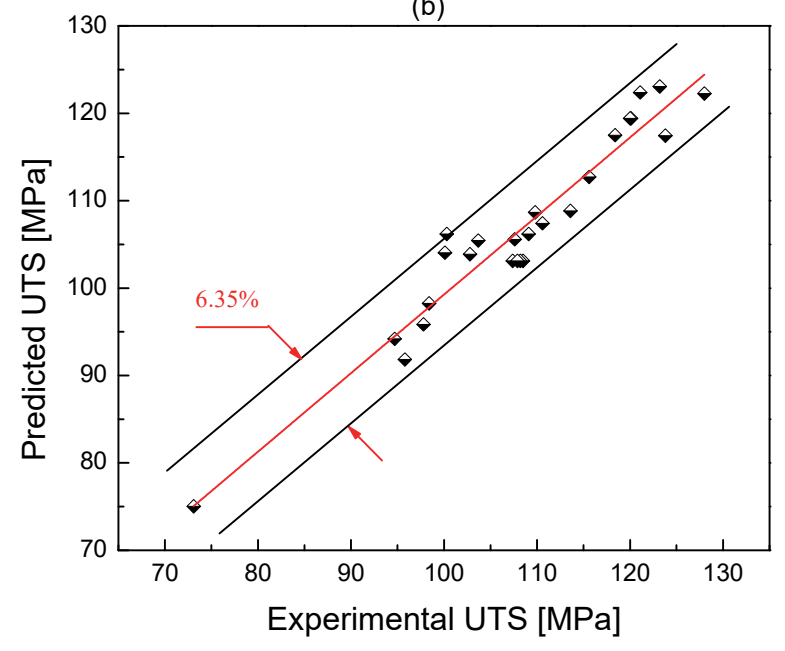

(c)

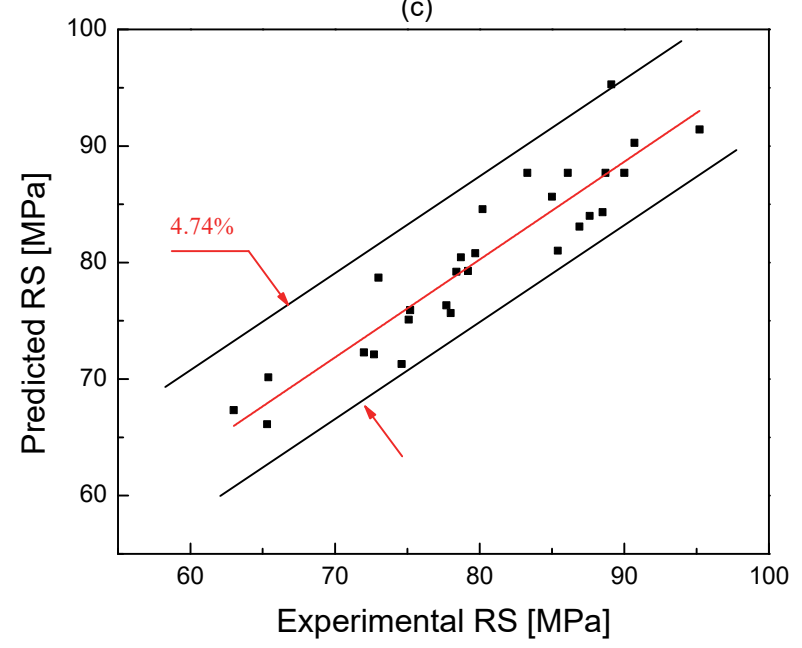

Figure 17: Predicted vs Experimental: a) Yield strength b) Ultimate tensile strength c) Rupture strength

\begin{tabular}{llcrrc}
\hline $\begin{array}{c}\mathrm{N} \\
{[\mathrm{rot} / \mathrm{min}]}\end{array}$ & $\begin{array}{c}\mathrm{S} \\
{[\mathrm{mm} / \mathrm{min}]}\end{array}$ & $\begin{array}{c}\mathrm{T} \\
\left.{ }^{\circ}\right]\end{array}$ & $\begin{array}{c}\mathrm{UTS} \\
{[\mathrm{MPa}]}\end{array}$ & $\begin{array}{c}\mathrm{YS} \\
{[\mathrm{MPa}]}\end{array}$ & $\begin{array}{c}\mathrm{RS} \\
{[\mathrm{MPa}]}\end{array}$ \\
1087,13 & 399,997 & 0,7508 & 116,771 & 49,9487 & 83,489 \\
1685,85 & 200,015 & 1,3552 & 122,24 & 41,8872 & 91,1325 \\
1694,02 & 200 & 1,281 & 122,59 & 41,7067 & 91,047 \\
1900 & 400 & 2,0999 & 122,156 & 39,5626 & 86.7125 \\
1423,93 & 400 & 1,2885 & 121,186 & 55,3134 & 94,6581 \\
1087,13 & 399,997 & 0,7508 & 116,771 & 49,9487 & 83,489 \\
1799,9 & 200 & 1,4948 & 122,716 & 41,8335 & 89,989 \\
1600 & 400 & 1,5 & 118,225 & 42,2038 & 94,8028 \\
\hline
\end{tabular}

Table 6: Optimal values for the mechanical properties of the welded joint 


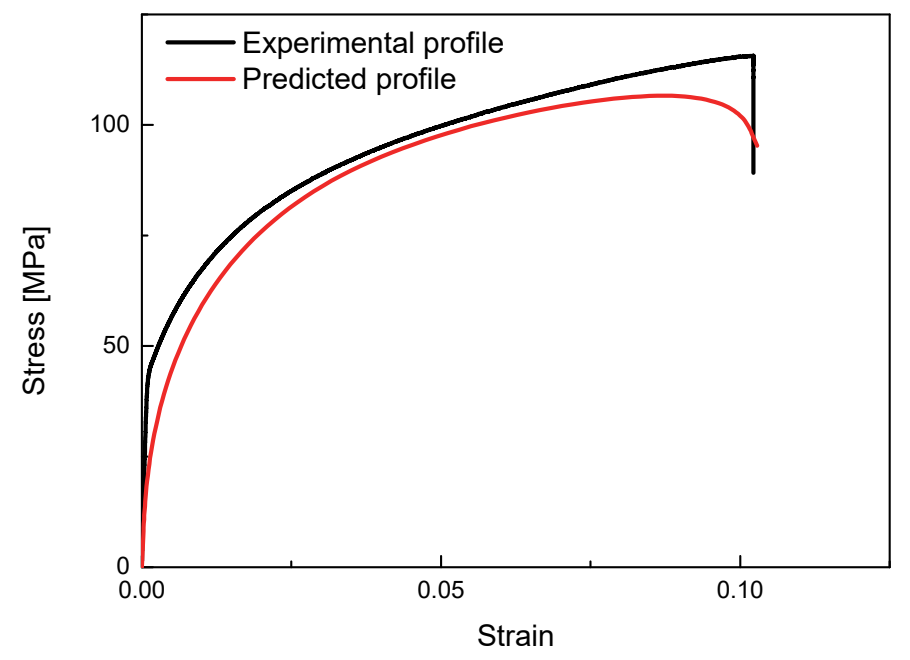

Figure 18: Predicted and experimental values of the stress-strain curve

\section{CONCLUSIONS}

7 his work focuses on the friction stir welding (FSW) process of aluminum 3003. This study mainly concentrates on the influence of three parameters, namely rotational speed, feed rate and tool tilt angle. The main purpose of this investigation was to understand and explain the interactions between the three parameters mentioned above, and to highlight the influence of each one of them on the others. The mechanical properties, such as the yield stress, ultimate tensile stress, and rupture strength, of the joints were studied in this context.

A mathematical model is proposed to predict the mechanical behavior of the junction using response surface methodology (RSM). This model is used to determine the optimal values of these parameters that are responsible for the better performance of the FSW joint.

Optimization of the welding process parameters suggests that:

- The tensile properties of friction stir-welded joints remain relatively good. In addition, the findings indicate that rupture most often takes place near the thermo-mechanically affected zone (ZATM). The most influential parameters are in the order of the rotational speed, feed rate and tool tilt angle.

- The model developed by the Design of Experiments approach made it possible to obtain a better prediction of the mechanical behavior of a welded joint. This model provides an effective tool for selecting the optimal parameters of the friction stir welding (FSW) process.

- The optimized parameter values that allow obtaining the best mechanical properties of a welded joint correspond to the values of $N=1423.93 \mathrm{rot} / \mathrm{min}, S=400 \mathrm{~mm} / \mathrm{min}$ and $T=1.2885^{\circ}$.

- The combinations of the different factors for a better quality of the FSW joint by obtaining a tensile strength of the weld joint equal to $75 \%$ of that of the base metal.

In continuing the development of these projects. It is interesting to study the effect of these parameters on expected heat input, temperature and material flow.

\section{REFERENCES}

[1] Pashazadeh, H., Teimournezhad, J., Masoumi, A. (2017). Experimental investigation on material flow and mechanical properties in friction stir welding of copper sheets, Int. J. Adv. Manuf. Technol., 88(5-8), pp. 1961-1970. https://doi.org/10.1007/s00170-016-8913-9.

[2] Palanivel, R., Mathews, P.K., Murugan, N., Dinaharan, I. (2012). Effect of tool rotational speed and pin profile on microstructure and tensile strength of dissimilar friction stir welded AA5083-H111 and AA6351-T6 aluminum alloys, Mater. Des., 40, pp. 7-16. http://dx.doi.org/10.1016/j.matdes.2012.03.027. 
[3] Zhang, Z.H., Li, W.Y., Li, J.L., Chao, Y.J. (2014). Effective predictions of ultimate tensile strength, peak temperature and grain size of friction stir welded AA2024 alloy joints, Int. J. Adv. Manuf. Technol., 73(9-12), pp. 1213-1218. https://doi.org/10.1007/s00170-014-5926-.0

[4] Buszta, S., Myśliwiec, P., Śliwa, R.E., Ostrowski, R. (2019). The Influence of Geometrical Parameters and Tools Material on the Quality of the Joint Made by FSW Method in AA2024 Thin Sheets, Arch. Metall. Mater., 64.

DOI: $10.24425 /$ amm.2019.127617

[5] Rajakumar, S., Balasubramanian, V. (2012). Predicting grain size and tensile strength of friction stir welded joints of AA7075-T6 aluminium alloy, Mater. Manuf. Process., 27(1), pp. 78-83. DOI: 10.1080/10426914.2011.557123

[6] Rajakumar, S., Muralidharan, C., Balasubramanian, V. (2010). Establishing empirical relationships to predict grain size and tensile strength of friction stir welded AA 6061-T6 aluminium alloy joints, Trans. Nonferrous Met. Soc. China, 20(10), pp. 1863-1872. DOI: 10.1016/S1003-6326(09)60387-3

[7] Elatharasan, G., Kumar, V.S.S. (2013). An experimental analysis and optimization of process parameter on friction stir welding of AA 6061-T6 aluminum alloy using RSM, Procedia Eng., 64, pp. 1227-1234.

DOI: $10.1016 /$ j.proeng.2013.09.202

[8] Verma, S., Misra, J., Gupta, M. (2019). Study of Temperature Distribution and Parametric Optimization during FSW of AA6082 Using Statistical Approaches, SAE Int. J. Mater. Manuf, 12(1), pp. 57-72. DOI: 10.4271/05-12-01-0005

[9] Krasnowski, K., Sędek, P., Lomozik, M., Pietras, A. (2011). Impact of selected FSW process parameters on mechanical properties of 6082-t6 aluminium alloy butt joints, Arch. Metall. Mater., 56, pp. 965.

[10] Krasnowski, K. (2014). Fatigue and static properties of friction stir welded aluminium alloy 6082 lap joints using Triflute-type and smooth tool, Arch. Metall. Mater., 59(1), pp. 157-62. DOI: 10.2478/v10172-011-0106-9

[11] Jannet, S., Mathews, P.K., Raja, R. (2015). Optimization of process parameters of friction stir welded AA 5083-O aluminum alloy using Response Surface Methodology, Bull. Polish Acad. Sci. Tech. Sci., pp. 851-855.

DOI: $10.1515 /$ bpasts-2015-0097

[12] Babu, N., Karunakaran, N., Balasubramanian, V. (2017). A study to estimate the tensile strength of friction stir welded AA 5059 aluminium alloy joints, Int. J. Adv. Manuf. Technol., 93(1-4), pp. 1-9. DOI: 10.1007/s00170-015-7391-9

[13] Safeen, W., Hussain, S., Wasim, A., Jahanzaib, M., Aziz, H., Abdalla, H. (2016). Predicting the tensile strength, impact toughness, and hardness of friction stir-welded AA6061-T6 using response surface methodology, Int. J. Adv. Manuf. Technol., 87(5-8), pp. 1765-1781. DOI: 10.1007/s00170-016-8565-9

[14] Patil, C., Patil, H., Patil, H. (2016). Experimental investigation of hardness of FSW and TIG joints of Aluminium alloys of AA7075 and AA6061, Frat. Ed Integrità Strutt., 10(37), pp. 325-32. DOI: 10.3221/IGF-ESIS.37.43

[15] Singh, H.N., Kaushik, A., Juneja, D. (2019). Optimization of process parameters of friction stir welded joint of AA6061 and AA6082 by response surface methodology (RSM). DOI10.36037/IJREI.2019.3610.

[16] Kadaganchi, R., Gankidi, M.R., Gokhale, H. (2015). Optimization of process parameters of aluminum alloy AA 2014T6 friction stir welds by response surface methodology, Def. Technol., 11(3), pp. 209-219.

DOI: $10.1016 / j . d t .2015 .03 .003$

[17] Heidarzadeh, A., Khodaverdizadeh, H., Mahmoudi, A., Nazari, a E. (2012). Tensile behavior of friction stir welded AA 6061-T4 aluminum alloy joints, Mater. Des., 37, pp. 166-173. DOI: 10.1016/j.matdes.2011.12.022

[18] Elangovan, K., Balasubramanian, V., Babu, S. (2009). Predicting tensile strength of friction stir welded AA6061 aluminium alloy joints by a mathematical model, Mater. Des., 30, pp. 188-193. DOI : 10.1016/j.matdes.2008.04.037

[19] Srujan Manohar, M.V.N., Mahadevan, K., (2020). Prediction on mechanical and microstructural behaviour of friction stir welded thin gauge aluminium-copper sheets, Mater. Today: Proc. DOI: 10.1016/j.matpr.2020.02.742.

[20] MODDE 5.0, Modelling and Design, Umetrics AB, Umea, Sweden. (1999).

[21] Mishra, R.S., Ma, Z.Y. (2005). Friction stir welding and processing, Mater. Sci. Eng. R Reports, 50(1-2), pp. 1-78. DOI: $10.1016 /$ j.mser.2005.07.001

[22] Takhakh, A.M., Abdullah, A.M. (2012). The Optimization Conditions of Friction Stir Welding (FSW) for Different Rotational and Weld speeds, Al-Nahrain J. Eng. Sci., 15(2), pp. 187-96.

[23] Abnar, B., Kazeminezhad, M., Kokabi, A.H. (2015). Effects of heat input in friction stir welding on microstructure and mechanical properties of AA3003-H18 plates, Trans. Nonferrous Met. Soc. China, 25(2147), pp. 2155.

DOI: $10.1016 /$ S1003-6326(15)63826-2

[24] Birol, Y., Kasman, S. (2013). Effect of welding parameters on the microstructure and strength of friction stir weld joints in twin roll cast EN AW Al-Mn1Cu plates, J. Mater. Eng. Perform., 22(10), pp. 3024-3033.

DOI: $10.1007 /$ s11665-013-0607-y

[25] Van Haver, W., Stassart, X., De Meester, B., Dhooge, A. (2008). Friction stir welding of aluminium high pressure die castings: Parameter optimisation and gap bridgeability, Weld. World, 52(9-10), pp. 20-9. DOI: 10.1007/BF03266665. 